\title{
Modelos de Financiamento Baseados em Relações Pessoais: Experiência de Empreendedores Chineses no Brasil
}

\section{Relationship-based Financing Models: Experiences of Chinese Entrepreneurs in Brazil}

\section{Hsia Hua Sheng*}

Doutor em Administração de Empresa pela FGV-EAESP. Professor de finanças da FGV-EAESP, São Paulo/SP, Brasil. Consultor sênior da MAPS Risk Management Solutions.

*Endereço: FGV-EAESP, Departamento de CFC, Rua Itapeva, 474, $8^{\circ}$ andar, São Paulo/SP, 01332-000. E-mail: Hsia.Sheng@fgv.br 


\title{
ResUMo
}

Diferentemente dos relacionamentos sociais que ocorrem normalmente no Ocidente, os relacionamentos que ocorrem na China, chamados guanxi, são uma forma especial de conexão, baseados na confiança, na qual são envolvidas sucessivas trocas de favores. O guanxi até hoje apresenta uma forte influência sobre o comportamento dos chineses, principalmente nos negócios. Essa particularidade cultural é refletida nos modelos de financiamentos informais, um dos responsáveis pelo crescimento de Pequenas e Médias Empresas [PMEs] na China. O objetivo do artigo é analisar empiricamente os modelos de financiamento baseados em guanxi no Brasil. Para isso utiliza-se o método exploratório, a partir de entrevistas realizadas com uma amostra de empreendedores chineses que possuem PMEs no Brasil. As evidências encontradas sugerem: i) os empreendedores utilizam guanxi para terem acesso ao financiamento e reduzirem o custo de crédito; ii) os modelos mais utilizados são os empréstimos diretos e crédito comercial, sendo evitados os empréstimos bancários; iii) o ambiente institucional brasileiro influencia as disponibilidades dos modelos; iv) os empreendedores participam de eventos sociais para manutenção e aquisição de guanxi.

Palavras-chave: guanxi; financiamento; empreendimento; China.

\begin{abstract}
Differently of relationships that normally occur in Western country, the relationship that is quite common in China, named guanxi, is a special form of connection based on personal trust, which are involved successive exchange of favors. The Guanxi still strongly influences on the Chinese's businessman behavior. This characteristic is printed in informal financing models, which is one of the key factors responsible for Small and Medium Enterprises [SMEs] growth in China. The objective of the article is to analyze empirically guanxi-based model of financing in Brazil. For this purpose, the exploratory method was applied, a sample of interviews with Chinese SME's entrepreneurs in Brazil. The evidences suggests that: i) the entrepreneurs uses guanxi to have accesses to financing and to reduce cost of financing; ii) the commercial credits and direct loan are heavily used by Chinese entrepreneurs and the bank short term loans are avoided; iii) the Brazilian institutional environment influences the models; iv) the entrepreneurs often participate of socials events to keep getting guanxi.
\end{abstract}

Key words: guanxi; financing; entrepreneurship; China. 


\section{INTRODUÇÃO}

"Para começar um negócio não é necessário muito capital, se você tem xinyon, já é o bastante. As pessoas irão dar-lhe crédito financeiro" (Kiong \& Kee, 1998, p. 85).

Esta citação mostra como é importante entender o reflexo do aspecto cultural chinês nos negócios. O sistema social da China difere do Ocidente, pois não é baseado nem no indivíduo nem na sociedade, e sim no relacionamento. Diferentemente de relacionamentos sociais que ocorrem normalmente no Ocidente, na China ocorrem relacionamentos chamados guanxi, uma forma de conexão mais especial, uma sucessiva troca de favores entre duas pessoas, que até hoje apresenta forte influência no comportamento dos chineses, principalmente nos negócios, mesmo após o país ter sofrido inúmeras transformações sociais e políticas (King, 1996).

Uma característica essencial que faz parte da composição do relacionamento guanxi é a característica citada no primeiro parágrafo, o xinyon (confiança). Negócios com pessoas de confiança são feitos sem regras e contratos formais. As formalidades são aplicadas somente àquelas pessoas que não são familiares ou confiáveis (Kao, 1991).

Quanto maior as relações de guanxi, mais fácil para empreendedores, proprietários e administradores obterem sucesso no ambiente empresarial. Relações múltiplas de guanxi não só aumentam a oportunidade para a interação, mas também os sentimentos em comum entre as partes, facilitando o desenvolvimento de confiança. Múltiplos guanxi são também muito mais consolidados do que um único guanxi (Jacobs, 1979).

O guanxi tem sido visto como uma das variáveis explicativas para o sucesso do desenvolvimento e expansão das Pequenas e Médias Empresas [PMEs] da China que, por sua vez, contribuiu para manter elevadas taxas de crescimento econômico e desenvolvimento da China (crescimento do PIB per capita anual médio de $8,1 \%$ ), após a reforma econômica de 1978. De acordo com o Departamento Estatístico da China, em 2003, as PMEs corresponderam a 99\% do número total de empresas registradas, produziram $60 \%$ do valor da produção industrial, geraram $60 \%$ do valor total de exportação e forneceram $75 \%$ de empregos totais formais nas áreas rurais e urbanas.

Uma das explicações para tal sucesso é que o guanxi, por meio de financiamento 
informal, amenizou o problema da falta de capital das PMEs na China. Várias modalidades de financiamentos baseadas em guanxi são utilizadas. De acordo com uma pesquisa da Universidade de Finanças e Economia Central (2001), que analisou uma amostra coletada nas 20 províncias chinesas, o volume proveniente de mercado informal de crédito é responsável por 30\% a $40 \%$ dos créditos totais usados por PMEs. As principais razões pelos elevados níveis de créditos informais são: i) falta de uma estrutura de crédito regularizada que ofereça produtos bancários adequados; ii) falta de conhecimento avançado em gestão de crédito; iii) ausência de um sistema integrado de avaliação de rating; e iv) falta de administradores especializados.

Apesar de terem um mercado de crédito mais estruturado e mais desenvolvido, as PMEs no Brasil também enfrentam os problemas de financiamento. Suas principais questões são as relacionadas com este elenco: restrição de volume, prazo curto, elevada taxa de juros e exigência de garantias. Não se conhece a maneira pela qual os empreendedores chineses de PMEs, do Brasil, contornam essas dificuldades. Uma hipótese seria que os empreendedores chineses usariam um modelo de financiamento baseado em guanxi, para suprir sua necessidade de capital. Em outras palavras, esses empreendedores utilizam guanxi para ter acesso ao financiamento e reduzir o custo de crédito.

O objetivo do artigo é analisar empiricamente o modelo de financiamento baseado em guanxi no Brasil. Para isso utiliza-se o método exploratório, a partir de entrevistas realizadas com uma amostra de empreendedores chineses que possuem PMEs em São Paulo, Brasil.

O estudo sobre o funcionamento dos modelos de financiamentos informais da China no Brasil é inédito na literatura brasileira. A contribuição trazida pelo artigo é aprofundar mais conhecimentos sobre alguns assuntos, tais como o impacto que as características culturais exercem sobre os modelos de financiamentos de PMEs e a administração de conflitos entre acionistas e credores, que incorporam aspectos culturais.

Este artigo está organizado da seguinte maneira: na primeira seção, são descritas as características do relacionamento guanxi, evidenciando os aspectos da sua estrutura organizacional, da sua formação, da sua manutenção e das suas contribuições para os empreendimentos chineses sob aspectos financeiros. Também serão apresentados os principais modelos de financiamentos informais na China. Na segunda seção, é descrito o caráter exploratório deste trabalho, fazendo parte dessa seção a metodologia e a amostra. Na terceira seção, os resultados dessa experiência piloto são discutidos e analisados. Por fim, na última seção, são descritas as conclusões. 


\section{Funcionamento, Aquisição e Manutenção de GuanXI}

O guanxi é um tipo especial de relacionamento entre pessoas. Além de ser muito comum, é considerado de extrema importância na China; baseia-se principalmente na confiança pessoal e funciona por meio de troca de favores mútuos ou em ciclo em um período de tempo (Carlisle \& Flynn, 2005). Esses favores são de extrema importância para a vida dos chineses, sendo muitas vezes consideradas ajudas essenciais ou vitais (Yeung, 2006). Há uma troca mútua de favores nos relacionamentos guanxi; algumas vezes a troca pode beneficiar uma terceira pessoa, para que, assim, se possa completar o ciclo de favores. É um ciclo dinâmico.

Uma vez que cada indivíduo na China é ao mesmo tempo devedor e provedor, há necessidade constante de manejar este equilíbrio interpessoal de donativodívida (King, 1996).

O ciclo de favores consiste em uma espécie de ajuda ao próximo, e é encerrado somente quando o número de ajudas concedidas se igualar ao número de ajudas adquiridas, podendo, portanto, o ciclo de favores envolver, para sua formação, duas ou mais pessoas. Em outras palavras, todos os que participam do ciclo (intencional ou não) prestam favor e recebem o favor, proveniente do ciclo.

A desconfiança gerada pela assimetria de informação pode deixar o ciclo fraco. Já que nem sempre a pessoa que oferece o favor é a mesma que vai receber, isso implica que todos os participantes teriam que ter o conhecimento da existência desse ciclo; mas isso pode não ocorrer, devido à assimetria de informação num ciclo grande, em que várias pessoas estão envolvidas.

Conseqüentemente, para atingirem esse equilíbrio no ciclo, além do mecanismo de funcionamento, é preciso que as pessoas convivam numa sociedade em que as pessoas (incluindo a própria pessoa) sigam simultaneamente os seguintes aspectos.

a) Possuir a crença de ajudar o próximo e ter gratidão ao receber, considerando a crença e ajuda como filosofia de vida. Essa crença ajuda e favorece o funcionamento do ciclo (Figura 1). A pessoa I não necessariamente conhece a pessoa II, ou está ciente de que estava no ciclo de favores; mas ajuda, de acordo com seus princípios éticos e morais. Essa predisposição mantém cada pedaço (cada favor) do ciclo funcionando (Whyte, 1995).

b) A ajuda é direcionada por certos atributos. As pessoas não oferecem favores aleatoriamente, mas oferecem-nos às pessoas que tenham atributos conhecidos e favoráveis. Esses atributos serão discutidos nos próximos parágrafos. Essa 
não aleatoriedade favorece a formação de um ciclo mais estável e reduzido, de tal forma que a pessoa I receba de volta seus favores mais facilmente, encerrando assim o ciclo (Kiong \& Kee, 1998).

\section{Figura 1: Ciclo de Favores que Envolveram Seis Pessoas para Poder ser Completada e Atingir o Equilíbrio}

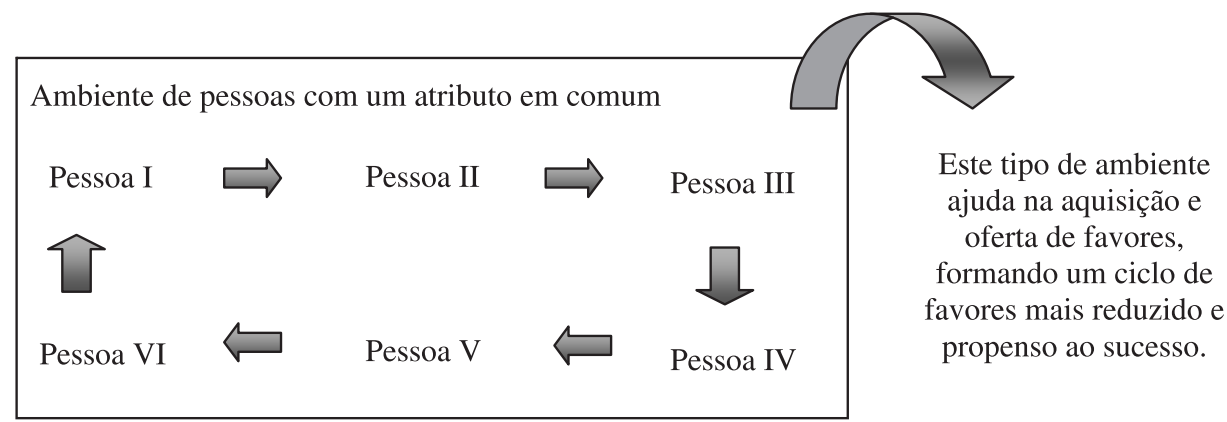

Obs: cada seta equivale a uma ajuda concedida.

Figura elaborada pelo autor.

O relacionamento guanxi pode ser criado involuntária ou voluntariamente. Para este último, o primeiro passo é a aquisição de atributos, que são características que alguns indivíduos possuem para estar dentro de um grupo de relacionamento. Um grupo de relacionamento sempre apresenta em comum alguns atributos. Os atributos podem ser adquiridos no nascimento ou no decorrer da vida (King, 1996).

Os atributos mais comuns entre as pessoas que aparecem no mundo dos negócios são residir próximo um do outro, possuir parentesco, ser colegas de trabalho ou colegas de sala de aula, ter o mesmo sobrenome e estar numa relação professor-estudante (Kiong \& Kee, 1998).

Cada pessoa classifica os diferentes tipos de atributos de maneira diferente, ou seja, nem sempre certo atributo é valioso o bastante para conseguir guanxi com uma pessoa, mas pode ser para outra.

Muitas vezes, uma pessoa pode não ter atributo nenhum com outra, e precisará de um intermediário (jên-ch'ing) para construir um mecanismo de rede de comunicações e de relacionamento. Podemos classificar então o jên-ch'ing como um relacionamento menos social, diferentemente do guanxi, que é um relacionamento mais sentimental, envolve a confiança e leva mais tempo para ser construído, apesar de ambos sempre estarem interligados (King, 1996).

O guanxi pode envolver uma relação de troca econômica e troca social; já o jên-ch'ing refere-se à troca econômica, desde que a troca seja feita por 
meio de racionalidade de mercado impessoal. Às vezes o jên-ch'ing entre duas pessoas pode ser apenas um início para se obter um guanxi entre elas (King, 1996).

A construção de guanxi e da confiança pessoal requer muito tempo e envolve várias etapas. Primeiro, você precisa conhecer a pessoa, testar o relacionamento e devagar ganhar a confiança.

Por fim, uma vez construído o guanxi, é necessário mantê-lo. Para isso é necessária uma interação social contínua, como visitas sociais e convites para jantar. O envio de presentes também facilita o processo. Sem essa interação social contínua, o guanxi se torna cada vez mais distante e pode gradualmente desaparecer. Outro fator, que é sem dúvida o mais importante para se manter um relacionamento guanxi, é a manutenção da confiança (Kiong \& Kee, 1998).

A ajuda mútua também é crucial para se manter o guanxi, os recursos alocados não devem ser unidirecionais; além disso, o retorno dos favores deve ser feito no tempo necessário. Portanto a segurança de dependência mútua também é crucial para se manter um guanxi (Hwang, 1987).

A Tabela 1 resume os princípios básicos para atingir os objetivos relacionados ao guanxi, como sua aquisição, construção e manutenção.

\section{Tabela 1: Princípios Básicos do Relacionamento Guanxi}

\begin{tabular}{|l|l|}
\hline \multicolumn{1}{|c|}{ Objetivos } & \multicolumn{1}{|c|}{ Procedimentos necessários } \\
\hline Aquisição do Guanxi & Possuir atributos ou Jên-ch'ing. \\
\hline Construção do Guanxi & $\begin{array}{l}\text { Conhecer a pessoa que quer se relacionar, ser paciente } \\
\text { para cultivar o bom relacionamento (pois pode } \\
\text { demorar muito tempo), ser testado e devagar ganhar } \\
\text { confiança. }\end{array}$ \\
\hline Manutenção do Guanxi & $\begin{array}{l}\text { Interação social contínua (visitas sociais, convite para } \\
\text { jantar), envio de presentes, ajuda mútua e o mais } \\
\text { importante e crucial: manter a confiança pessoal. }\end{array}$ \\
\hline
\end{tabular}

Fonte: King (1996); Kiong e Kee (1998). Tabela elaborada pelo autor.

No item a seguir, será discutido como essa característica cultural se reflete no ambiente de negócio, especificamente no financiamento de PMEs.

\section{Modelos de Financiamento Baseados em Guanxi}

A relação de guanxi é recíproca e se tornou um jeito de fazer negócios entre os chineses, criando economicamente funções de rede de contatos. Yeung (2006) 
considerou o relacionamento guanxi como se fosse o sangue vital dos negócios chineses, enfatizando também que a confiança e a comunicação fornecidas pelo guanxi são a peça-chave para a transferência de conhecimento, especialmente no mundo dos negócios.

Os homens de negócio chineses acreditam que a confiança interpessoal e o ciclo de relacionamento minimizam fraudes e asseguram certa ordem. Por meio do guanxi as transações podem ser feitas informalmente. Podem-se até fechar grandes negócios com um simples telefonema. Para os comerciantes chineses, o principal é a integridade e a credibilidade (Kiong \& Kee, 1998).

Esse raciocínio também é aplicado nas atividades de financiamentos, principalmente pelas PMEs. Os empresários chineses acreditam que o guanxi amplia o acesso de crédito ou reduz o custo de crédito. Eles também acreditam que o guanxi substitui a necessidade de um contrato formal entre credor e tomador.

Nesse contexto, ao contrário dos mercados de créditos formais, que utilizam a teoria de contratação financeira, especificamente a análise de estrutura de contrato para minimizar os custos de conflitos entre credores e acionistas (Harris \& Raviv, 1993), o mercado de crédito informal chinês usa a força do guanxi para resolver os conflitos. Em outras palavras, o guanxi administra os problemas de agências relacionados com os três fatores da empresa financiada, que são incorporados nas cláusulas contratuais. Esses fatores são alavancagem, reputação e controle.

a) Fator alavancagem. A alavancagem financeira, a proporção da dívida na estrutura de capital, afeta o grau de incentivo para o investimento de uma empresa. Jensen e Meckling (1976) apontaram o efeito do incentivo em empresas excessivamente alavancadas como uma das causas do alto custo da agência de dívidas. Com tal estrutura de capital, os administradores que agem conforme as decisões dos acionistas recebem fortes incentivos para investir em projetos arriscados.

b) A reputação. A reputação é medida pela qualidade histórica e pelo tempo de crédito de uma empresa. Uma empresa nova, de baixo rating, provavelmente utilizará uma ferramenta mais custosa para reduzir o conflito, usando contratos restritivos. No entanto, para as novas emissoras, com a evolução do tempo, é possível também reduzir esse conflito por meio da reputação adquirida. John e Nachman (1985) estão entre os primeiros que formalizaram a hipótese de que a reputação pode alinhar os interesses entre credores e acionistas. 
c) Fator de controle. O mecanismo de alocações de controle entre acionistas e credores também influencia o rating. Os credores exigem cláusulas de controle de empresas com baixo nível de rating. As teorias de controle partem da hipótese de que os detentores do direito de direção e do direito a voto decidem sobre quaisquer eventos que não estão especificados no contrato original. Grossman e Hart (1986) contribuíram com o primeiro trabalho teórico sobre o caráter incompleto dos contratos e do direito de controle. O desenvolvimento dessa teoria está fundamentado na impossibilidade de prever todos os eventos e no elevado custo para listar todos os direitos específicos sobre todos os ativos (contratação dispendiosa). Para resolver esse conflito a um custo ótimo, um dos participantes (agente ou principal) poderia comprar todos os direitos de fluxos de caixas residuais e passaria a deter o controle do ativo. Harris e Raviv (1989) e Zender (1991) também derivaram teoricamente a alocação ótima de direito de controle.

Os modelos baseados em guanxi mais comuns na China são descritos num relatório do Banco Central da China (2005). Foi feito um estudo de caso detalhado sobre um dos pólos de desenvolvimento econômico mais bemsucedido da China: o caso de Wen-Thou. Esses modelos explicitam-se em seguida.

a) Empréstimo direto. Essa é a modalidade mais antiga e mais comum. $\mathrm{O}$ acerto, sobre a taxa de juros, o prazo e o volume, é direto entre o tomador e o credor. A base de expansão é construída sobre a confiança e entendimento mútuos. Essa modalidade pode ser subdividida em empréstimos com juros e empréstimos sem juros para giro de capital. Este último é praticado para alocar recursos entre familiares, parentes e amigos próximos. Esse tipo de empréstimo é comum na China, não importando o local e o nível de desenvolvimento da região.

b) Huei. É o tipo de financiamento mais comum da China. Ele funciona como um tipo de consórcio, no qual o líder organizador desse consórcio convida seus amigos e parentes para fazerem parte; estes, por sua vez, convidam mais amigos (com guanxi) para entrar. Cada um dos consociados contribui com uma quantia, e a quantia total será utilizada, na primeira rodada e sem pagamento de juros, pelo líder. O não pagamento de juros seria uma espécie de pagamento da taxa de administração pelos consorciados. Depois da primeira rodada, o volume total pode ser leiloado por taxa de juros mensais ou por uma ordem pré-definida antes da organização do consórcio. Nessa organização, devido ao bom guanxi, os riscos de crédito de todos os consorciados são considerados iguais. 
c) Capital coletivo. Os administradores ou acionistas das PMEs organizam um fundo para captar recursos de funcionários da própria empresa, por determinado prazo e determinada taxa de juros e prêmio de participação. Geralmente, esse fundo possui um objetivo de investimento. Alguns integram esse fundo no capital próprio da empresa.

d) Agência de intermediação de capital. Essas agências captam recursos, vendem crédito e operam no mercado informal. Os proprietários conhecem bem o mercado local e usam sua rede de contatos para aproveitar as necessidades distintas em localidades específicas.

e) Cooperativas de crédito rural. Essas cooperativas só funcionam nas regiões rurais que já atingiram certo nível de desenvolvimento, de tal forma que os associados tenham acumulado recursos razoáveis para financiar o capital de giro de empresa que demanda crédito. O público alvo são as PMEs na área rural.

Somente nos dois primeiros modelos, no empréstimo direto e no huei, o guanxi facilita o financiamento de empreendedores, tanto no acesso quanto no custo de empréstimos. Nas outras modalidades, os empreendedores conseguem acesso, mas não necessariamente as melhores taxas. $\mathrm{O}$ mesmo relatório do Banco Central da China (2005), também declara que, recentemente, com exceção de empréstimos diretos, as outras modalidades de empréstimos têm reduzido suas participações no mercado de crédito informal, devido principalmente à diversificação de produtos de empréstimos bancários para PMEs e ao aumento de agências de intermediação financeiras autorizadas (cooperativas, por exemplo) nas localidades em que antes não eram acessíveis tais empréstimos.

Baseado nestas informações, surge a hipótese de que a utilização desses modelos facilitaria os acessos de créditos para os empreendedores chineses de PMEs no Brasil.

\section{Metodologia e Amostra}

Trata-se de um estudo exploratório, em que foram abordadas as condições e características dos relacionamentos pessoais dos entrevistados, e se elas afetam as formas de financiamentos de seus empreendimentos. A pesquisa teve abordagem qualitativa.

Por ser pesquisa de campo exploratória, o estudo não visa à confirmação de hipótese; tem como finalidade, além de aprofundar o conhecimento de guanxi 
sobre financiamentos das PMEs chinesas no Brasil, servir de base a uma futura pesquisa, ajudando a formulação de hipóteses ou o esclarecimento de idéias em estudos semelhantes.

Utilizou-se como critério de inclusão o empreendedor nascido e criado na China, que recebe as tradições culturais chinesas em sua infância e abriu seus negócios no Brasil, mais especificamente no centro da cidade de São Paulo (Rua 25 de Março e bairro da Liberdade). Utilizou-se como critério de exclusão o empreendedor chinês que deixou de responder ao instrumento e não assinou o termo de consentimento autorizando sua participação na pesquisa.

Todos os empreendedores chineses envolvidos na pesquisa assinaram um termo de consentimento esclarecido, em que autorizam sua participação na pesquisa, tendo plena consciência dos objetivos do pesquisador. Foi garantido o absoluto anonimato dos entrevistados.

A coleta de dados foi feita por meio de entrevistas, utilizando-se como base para estas entrevistas um instrumento com perguntas dissertativas que pudessem trazer informações sobre fontes de financiamento e guanxi. O instrumento (Anexo 1) contém 18 perguntas, e a coleta de dados foi realizada nos meses de fevereiro e março de 2006 pelo próprio pesquisador que, inicialmente, explicou a finalidade do estudo e, posteriormente, entregou o instrumento para que o empreendedor conhecesse seu conteúdo. Após um dia, era marcada uma entrevista. Dessa forma, a pesquisa foi realizada no próprio local de trabalho do empreendedor.

Para análise dos dados, utilizamos a técnica de análise de conteúdo, pelo fato de essa possibilitar a busca dos significados, a partir dos relatos dos entrevistados. Estes relatos foram analisados em categorias, sendo analisadas todas as respostas e os comentários emitidos pelos entrevistados. Assim, buscou-se compreender a relação dos relacionamentos guanxi com a forma de financiamento dos empreendedores chineses no Brasil.

\section{AnÁlise e Interpretação dos Resultados}

Buscou-se compreender a utilização de guanxi por empresários de PMEs, para captar recursos para seus negócios. Foram utilizadas três categorias de análises para agrupar os principais relatos dos entrevistados, possibilitando o alcance dos objetivos específicos do estudo. A Tabela 2 descreve as três categorias de análise. 


\section{Características dos Empreendedores}

Foram procurados 30 empreendedores chineses; apenas sete aceitaram participar da entrevista. Os empreendedores se mostraram muito desconfiados, característica comum do povo chinês, já que o tema envolvido na pesquisa era sobre assuntos muito pessoais e sobre dinheiro, e a grande maioria não se sentiu à vontade para comentar.

Tabela 2: Categoria de Análise

\begin{tabular}{|l|l|l|}
\hline \multicolumn{1}{|c|}{ Categoria } & \multicolumn{1}{|c|}{ Elementos-chave } & \multicolumn{1}{c|}{ Objetivos específicos } \\
\hline Empreendedor & $\begin{array}{l}\text { Idade/Experiência/Ramo/Tamanho } \\
\text { do Empreendimento }\end{array}$ & $\begin{array}{l}\text { Caracterizar a experiência } \\
\text { dos empreendedores }\end{array}$ \\
\hline $\begin{array}{l}\text { Guanxi dos } \\
\text { empreendedores }\end{array}$ & $\begin{array}{l}\text { Participação/Organização em } \\
\text { associações e eventos familiares e } \\
\text { de amigos }\end{array}$ & $\begin{array}{l}\text { Identificar Guanxi dos } \\
\text { empreendedores }\end{array}$ \\
\hline $\begin{array}{l}\text { Formas de } \\
\text { financiamento }\end{array}$ & $\begin{array}{l}\text { Empréstimo bancário/Empréstimo } \\
\text { direto/Huei/Crédito comercial e } \\
\text { outros }\end{array}$ & $\begin{array}{l}\text { Compreender o processo de } \\
\text { escolha de financiamento dos } \\
\text { empreendedores }\end{array}$ \\
\hline
\end{tabular}

Fonte: elaborado pelo autor.

$\mathrm{O}$ fato de três empreendedores se negarem a assinar o documento, como o termo de consentimento esclarecido, reforçou ainda mais a teoria de que os chineses não gostam de assinar nada e preferem a informalidade. Estes três empreendedores foram excluídos da amostra final. Por fim, este estudo teve como amostra $(\mathrm{n}=7)$ empreendedores (proprietário/administrador) chineses que abriram negócios no Brasil.

Os resultados das principais características do empreendedor e do seu empreendimento são descritos na Tabela 3. Para facilitar a análise, os entrevistados estão em ordem decrescente de tempo no empreendimento, ou seja, de experiência.

Dos empreendedores entrevistados, cinco apresentavam evidências de que seus negócios já estavam consolidados no ramo, pelo fato de apresentarem mais de sete anos de experiência. Devido à idade (maior de 48 anos), esses cinco entrevistados também possuem vasta experiência de vida e convívio social. Pela teoria discutida no item 1, a combinação dessas duas características favorece o surgimento de relações múltiplas de guanxi.

Três empreendedores mais experientes trabalham com um volume grande de negócios, uma vez que eles são atacadistas e importadores diretos da China. O entrevistado 1 comentou que as vendas para os chineses correspondem a uma parcela grande de seu faturamento, demonstrando sua experiência não só como comprador, mas também como fornecedor. Esses empreendimentos possuem em torno de 19 funcionários. 
Tabela 3: Características dos Entrevistados e seus Empreendimentos

\begin{tabular}{|c|c|c|c|c|c|}
\hline Entrevistado & $\begin{array}{l}\text { Idade } \\
\text { (anos) }\end{array}$ & $\begin{array}{c}\text { Tipo de } \\
\text { empreendimento }\end{array}$ & $\begin{array}{l}\text { Tempo (anos) de } \\
\text { empreendimento }\end{array}$ & $\begin{array}{c}\text { No. De } \\
\text { funcionários }\end{array}$ & $\begin{array}{c}\text { Importa } \\
\text { produtos da } \\
\text { China* }\end{array}$ \\
\hline 1 & 56 & $\begin{array}{c}\text { Bazar - } \\
\text { importados (A) }\end{array}$ & 25 & 16 & Sim \\
\hline 2 & 50 & $\begin{array}{c}\text { Loja de bijuterias } \\
\text { - misto }(\mathrm{A})\end{array}$ & 20 & 18 & Sim \\
\hline 3 & 53 & $\begin{array}{c}\text { Bazar - } \\
\text { importados }(\mathrm{A} / \mathrm{V})\end{array}$ & 15 & 22 & Sim \\
\hline 4 & 48 & $\begin{array}{l}\text { Bazar - misto } \\
\text { (V) }\end{array}$ & 8 & 3 & Não \\
\hline 5 & 50 & $\begin{array}{c}\text { Bazar - misto } \\
(\mathrm{V})\end{array}$ & 8 & 4 & Às vezes \\
\hline 6 & 31 & $\begin{array}{l}\text { Bazar - misto } \\
\text { (V) }\end{array}$ & 2 & 3 & Não \\
\hline 7 & 28 & $\begin{array}{l}\text { Bazar - misto } \\
\text { (V) }\end{array}$ & 2 & 2 & Não \\
\hline
\end{tabular}

Observação: $(\mathrm{A})$ = Atacado; $(\mathrm{V})$ Varejo; $(\mathrm{A} / \mathrm{V})=$ Atacado e Varejo; Misto = venda de produtos importados e não importados; importados $=$ vendas de produtos importados; $*$ importa produtos diretamente da China.

Tabela elaborada pelo autor.

No outro extremo, os dois mais jovens empreendedores, com dois anos de experiência, já conseguiram alcançar um tamanho de empreendimento, em termos de número de funcionários, próximo ao tamanho administrado pelos entrevistados 4 e 5 , que possuem oito anos de experiência.

Portanto, a amostra deste estudo engloba os empreendedores de todas as fases de desenvolvimento.

\section{Guanxi dos Empreendedores}

Os resultados mostram que os empreendedores chineses no Brasil, independentemente do tempo do empreendimento e do tamanho da empresa, procuram adquirir e manter guanxi conforme a teoria prevista na seção Modelos de Financiamento Baseados em Guanxi.

Baseado na Tabela 4, notou-se que todos costumam freqüentar pelo menos uma associação não religiosa. Essas associações possuem freqüentadores com algum tipo de atributos em comum. Foram citadas pelos entrevistados as seguintes associações: associação de golfe, associação de comerciantes chineses, associação de jovens chineses, associação de tênis, associação da terceira idade, associação de taiwaneses, associação de empresários e associação de Guantones. Há reuniões ou atividades regulares entre os associados. Somente o entrevistado 2 se projeta ativamente, uma vez que seu marido ocupa dois cargos nessas associações. 
Aproximadamente metade dos entrevistados freqüenta associação religiosa. As igrejas protestantes e os templos budistas são mais citados. O entrevistado 6, um empreendedor na fase inicial de empreendimento (Tabela 3), destacou o apoio emocional e o apoio financeiro incondicional recebido de seus irmãos da igreja.

Além das associações, com exceção do entrevistado 6, todos os empreendedores possuem um relacionamento com amigos e parentes, embora o grau de envolvimento seja diferente entre eles. Os entrevistados com maior tempo de empreendimento ligeiramente tendem a organizar mais eventos. Isso mostra que eles possuem guanxi mais forte que os demais, uma vez que são capazes de atrair seus amigos ou parentes para seus eventos. Se considerarmos que os amigos ou parentes também são do mesmo ramo, esse guanxi é mais forte ainda, e também mais valioso em termos comerciais. Todos os entrevistados com o tempo de empreendimento acima de 15 anos organizam alguns tipos de evento, enquanto somente alguns dos empreendedores com menos de 15 anos de experiência organizam eventos.

A Tabela 4 resume as características dos entrevistados em relação aos seus relacionamentos pessoais.

\section{Tabela 4: Características dos Entrevistados sobre os Relacionamentos Pessoais}

\begin{tabular}{|c|c|c|c|c|c|c|}
\hline Entr. & $\begin{array}{c}\text { No. De } \\
\text { associações } \\
\text { não religiosas } \\
\text { que freqüenta }\end{array}$ & $\begin{array}{c}\text { Quantos } \\
\text { cargos } \\
\text { possuem (nas } \\
\text { associações) }\end{array}$ & $\begin{array}{c}\text { Freqüenta } \\
\text { associações } \\
\text { religiosas }\end{array}$ & $\begin{array}{c}\text { Freqüenta } \\
\text { eventos de } \\
\text { amigos } \\
\text { (organiza } \\
\text { eventos) }\end{array}$ & $\begin{array}{c}\text { Freqüenta } \\
\text { eventos de } \\
\text { parentes } \\
\text { (organiza } \\
\text { eventos) }\end{array}$ & $\begin{array}{c}\text { Amigos e/ou } \\
\text { parentes no } \\
\text { ramo }\end{array}$ \\
\hline 1 & 1 & 0 & Sim & Sim (Sim) & Sim (Sim) & Sim \\
\hline 2 & 2 & $2^{*}$ & Não & Sim (Sim) & Sim (Não) & Sim \\
\hline 3 & 2 & 0 & Não & Sim (Não) & Sim (Sim) & Sim \\
\hline 4 & 1 & 0 & Sim & Sim (Sim) & Sim (Não) & Sim \\
\hline 5 & 4 & 0 & Sim & Sim (Não) & Sim (Não) & Sim \\
\hline 6 & 1 & 0 & Sim & Não (Não) & Sim (Não) & Sim \\
\hline 7 & 2 & 0 & Não & Sim (Sim) & Sim (Não) & Sim \\
\hline
\end{tabular}

Observação: Entr. $=$ Entrevistado.

* não possui cargos na associação, mas o marido ocupa dois cargos.

Tabela elaborada pelo autor.

\section{Formas de Financiamentos dos Empreendedores Chineses}

A seguir, foram feitas as seguintes perguntas:

\section{Como conseguiu capital para abrir seu negócio?}

As respostas são convergentes. A modalidade comentada por todos os 
entrevistados é o financiamento de empréstimos de amigos e parentes. Todos os entrevistados afirmaram já a terem utilizado. Segundo a amostra, geralmente, a taxa de juros é zero nos empréstimos entre parentes e é baixa nos empréstimos entre os amigos.

Este tipo de financiamento é utilizado basicamente para o capital inicial da empresa ou um projeto de investimento. A entrevistada 5 afirma que, em geral, não existe um contrato entre tomador e fornecedor de capital. Os empréstimos são feitos informalmente. $\mathrm{O}$ acesso ao capital e ao menor nível da taxa de juros depende de guanxi entre as duas partes. Quanto melhor guanxi, menor a taxa de juros e maior o volume. Geralmente, os fornecedores de capital são credores informais dos empreendedores, pois esse capital é registrado e integrado como capital próprio dos empreendedores no registro de empresas. Não há a interferência dos credores nas atividades gerenciais da empresa. Essa situação é diferente, quando os fornecedores manifestam o desejo de participar da sociedade. Nesse caso, esses fornecedores participarão da sociedade e da administração da empresa.

Contudo os empreendedores mais experientes não o utilizam mais por já terem acumulado seu capital próprio. Os dois empreendedores mais jovens disseram que o capital inicial foi fornecido pelos pais e uma pequena parte pelos amigos. $\mathrm{O}$ empreendedor 6 disse que, geralmente, pede empréstimos para vários parentes e amigos, e cada um contribui com uma pequena quantia.

Apesar de essa modalidade ser a mais utilizada entre os entrevistados, ela possui um contraponto. O empreendedor 3 comenta que, no seu caso, os empréstimos feitos por parentes e amigos são de iniciativa do fornecedor de empréstimo; o pedido direto de empréstimos, normalmente, não é considerado boa atitude; além disso, corre-se um risco de perder ou diminuir os laços de amizade. Atualmente, as pessoas ficam sensíveis, quando o assunto é dinheiro.

\section{Que tipo de financiamento bancário você utiliza? Comente.}

Em geral, os empreendedores chineses, do presente estudo, não utilizam empréstimos bancários, como fonte de financiamento de curto prazo. Observando a Tabela 5, nenhum entrevistado utiliza empréstimos bancários para capital de giro, com exceção do entrevistado 7. Notou-se que todos os entrevistados que não utilizam esta modalidade demonstraram um tom enérgico e bastante decidido, ao negarem a utilização desta modalidade, apesar da existência de disponibilidade de crédito na abertura de contas de pessoas jurídicas. A taxa de juros elevada é citada como o principal motivo de não pegar empréstimos bancários. O entrevistado 7 afirmou que apenas faz uso desse tipo de empréstimo (limite de crédito) em caso de extrema necessidade ou de descuido não voluntário, como quando os 
pais estavam em viagem e precisou cobrir um pagamento de um fornecedor, ou fazer pagamento de funcionário sem recurso disponível na conta corrente.

\section{Tabela 5: Modalidades de Financiamento Utilizados pelos Entrevistados}

\begin{tabular}{|c|c|c|c|c|}
\hline & \multicolumn{4}{|c|}{ Modalidades } \\
\hline Entrevistado & $\begin{array}{c}\text { Empréstimos } \\
\text { bancários (para } \\
\text { capital de giro) }\end{array}$ & $\begin{array}{c}\text { Consórcio } \\
(\mathrm{Huei})\end{array}$ & $\begin{array}{c}\text { Empréstimos de } \\
\text { amigos/parentes }\end{array}$ & $\begin{array}{c}\text { Fornecedor crédito } \\
\text { comercial (prazo) }\end{array}$ \\
\hline 1 & Não & Não* & Não* & Sim (a vista) \\
\hline 2 & Não & Não* & Não* & $\begin{array}{c}\text { Sim (a vista ou 180 } \\
\text { dias) }\end{array}$ \\
\hline 3 & Não & Não* & Não* & Sim (a vista) \\
\hline 4 & Não & Não* & Não* & $\begin{array}{c}\text { Sim (30 a } 120 \text { dias, } \\
\left.C^{*}\right)\end{array}$ \\
\hline 5 & Não & Não* & Sim (sem juros) & Sim (30 dias, C*) \\
\hline 6 & Não & Não & Sim (sem juros) & $\begin{array}{c}\text { Sim (30 a } 90 \text { dias, } \\
\text { C*) }\end{array}$ \\
\hline 7 & Sim, às vezes & Não & Sim (sem juros) & $\begin{array}{c}\text { Sim (30 a } 90 \text { dias, } \\
\text { C*) }\end{array}$ \\
\hline
\end{tabular}

Obs: Não* = Não utiliza hoje em dia, mas costumava utilizar antigamente.

$\mathrm{C}^{*}=$ consignado.

Os entrevistados também não fazem nenhum adiantamento de seus recebíveis com o banco. Os cheques pré-datados são utilizados para fazer pagamentos aos fornecedores nacionais antes da data, ou espera-se até a data acordada para a conversão de caixa, de acordo com o entrevistado 2. Os outros entrevistados, principalmente donos de lojas de varejos, evitam cheques pré-datados e preferem trabalhar com o pagamento a vista ou com o cartão, para evitar a inadimplência. Nenhum deles faz antecipação de recebíveis com as empresas de cartão de crédito. O entrevistado 4 comenta que ele prefere oferecer $5 \%$ de desconto para pagamento a vista a arcar com o risco de crédito de cheques.

\section{Que fontes de financiamento de curto prazo você utiliza (e utilizava)? Por quê? Comente.}

A modalidade de empréstimo direto entre parentes e amigos, reitere-se, é a mais comentada entre os entrevistados. Os entrevistados 5, 6 e 7 afirmam que os empréstimos diretos são para todas as situações. $\mathrm{O}$ entrevistado 1 comenta que pegava recursos com os parentes da China. Somente o entrevistado 3 continua com a visão mais realista do empréstimo.

A modalidade consórcio ( $h u e i$ ) não é utilizada por empreendedores chineses no Brasil, embora ela tenha sido importante e popular no passado. Os entrevistados 
com maior idade e maior experiência relataram que utilizavam quando iniciaram seus empreendimentos, mas que hoje em dia não utilizam mais, porque, além de não existirem, eles não necessitam (Tabela 5). O entrevistado 2 utilizou várias vezes huei para financiar o capital de giro no início de seu empreendimento.

O funcionamento do huei no Brasil é parecido com o da China. Os consorciados, em média, contribuíam com 1.000-2.500 reais (valores atuais equivalentes), e o grupo era formado de 30 a 40 pessoas. O organizador do consórcio tinha o direito de utilizar todo o volume do dinheiro, sem juros, logo na primeira rodada. A não cobrança de juros equivalia ao pagamento de comissão. A partir da segunda rodada, o volume total era leiloado para os consociados, e quem recebia era aquele que pagava a maior taxa de juros mensal.

A mudança de ambiente macroeconômico brasileiro foi um dos responsáveis pela queda do uso do huei. Segundo o entrevistado 2, o huei era muito atuante, quando havia no Brasil inflação elevada. Com a estabilização da economia, os fornecedores de recurso perderam o interesse devido à taxa de juros menor e ao aumento de inadimplência entre os associados.

$\mathrm{O}$ entrevistado 3 comenta que, devido às fraudes que ocorriam anteriormente nesta modalidade, alguns chineses estão mais receosos em utilizá-la hoje em dia. Essa situação foi confirmada pelos empreendedores mais jovens (entrevistados 6 e 7) que, ao mencionarem suas fontes de capital de giro, citaram outras fontes, mas não comentaram a utilização do huei.

\section{Mais algum tipo de ajuda de parentes/amigos são essenciais para seu negócio?}

Além de fornecerem o capital diretamente, os amigos e parentes são essenciais para conseguir maior prazo de pagamento de mercadorias. Todos os entrevistados comentam que utilizam guanxi para conseguir crédito comercial (fonte espontânea de financiamento) ou fornecedores. Guanxi pode ajudar diretamente, se o fornecedor é seu amigo ou parente. Por exemplo, o entrevistado 3, por ser atacadista, considera aceitável um pedido de crédito comercial como forma de ajudar alguém de sua família ou de seus amigos. Segundo ele, as pessoas estão se tornando cada vez mais realistas. Há uma tendência em rejeitar os pedidos de empréstimos diretos, mas em aceitar fornecer mercadorias em prazo maior ou fazer uma venda consignada.

Guanxi também ajuda indiretamente. Os pais do entrevistado 6 são conhecidos na comunidade religiosa. Apesar de não ter muita experiência no ramo, o empreendedor 6 conseguiu prazos longos e mercadorias consignadas com vários fornecedores. 
Aparentemente, há uma contradição nos resultados. Observando a Tabela 5, nota-se que os empreendedores com maior tempo de experiência, e com empreendimentos mais consolidados, não possuem crédito de fornecedor. A explicação está no fato de o fornecedor poder ser nacional ou internacional (China). De acordo com o entrevistado 2, as grandes empresas estatais, na China, podem até fornecer crédito acima de seis meses, mas o volume de produtos tem que ser muito grande. Se o fornecedor é uma PME privada na China, e o pagamento é a vista, em geral pode até existir uma exceção para aqueles com bom guanxi, que pagam em até 30 dias, mas a regra geral é pagamento a vista. Por isso os importadores (na amostra são aqueles com maior experiência) pagam a vista. Esta versão é confirmada pelos outros dois atacadistas do estudo, que também pagam a vista.

Já quem utiliza um fornecedor nacional, no caso dos entrevistados 5, 6 e 7, a regra geral é pagamento entre 30 e 90 dias. O empreendedor 5 enfatiza que este prazo é para clientes que possuem guanxi; aqueles que não têm guanxi possuem 30 dias para pagar, durante 6 meses a 1 ano, para poder assim construir o crédito e também o guanxi; para aqueles que fazem o pagamento à vista do fornecedor, há descontos de $5-10 \%$, dependendo da mercadoria. O entrevistado 7 comenta que, além do maior prazo, existe mais flexibilidade, se você tiver um guanxi. Mas o entrevistado 4, que afirmou pagar em 30-120 dias, comenta que não há tanta distinção entre aqueles que têm e aqueles que não têm guanxi. Quando o assunto é o prazo de pagamento, no entanto, quem tem guanxi com o fornecedor consegue as melhores mercadorias, ou seja, aquelas que vendem mais.

\section{Conclusão}

Os empreendedores chineses de PMEs do Brasil usam modelos de financiamento baseados em guanxi como a principal fonte de financiamento e não como uma fonte complementar, apesar de o Brasil possuir um mercado de crédito e um sistema bancário mais desenvolvidos que a estrutura de crédito na China.

Por causa da elevada taxa de juros do empréstimo bancário, os empreendedores chineses evitam todos os tipos de financiamentos bancários. Para contornar esse problema, os empreendedores chineses recorrem aos empréstimos diretos para financiar seu capital de giro, ou capital inicial ou projetos de investimentos. O empréstimo direto é feito de forma semelhante à operação realizada na China; não existe o contrato formal; o grau de guanxi entre as partes envolvidas determina o volume e o nível da taxa de juros. Em geral, a taxa de juros dos empréstimos entre parentes e amigos próximos é zero. 
Todos os entrevistados usam empréstimo direto, pois todos eles possuem bom guanxi. Esses empreendedores se envolvem e participam das reuniões sociais e religiosas da comunidade chinesa. Aqueles que possuem melhores guanxi não só participam regularmente, mas também organizam ou assumem cargos nas associações sociais e culturais. Todas essas atividades favorecem o desenvolvimento múltiplo de guanxi e a aquisição de mais atributos que são fundamentais para os negócios.

Outro modelo de financiamentos baseado em guanxi seria o huei, que foi bastante atuante na época de alta inflação. No entanto essa modalidade simplesmente desapareceu do mercado após a estabilização econômica brasileira.

Desde então, o crédito comercial, fonte espontânea de financiamento, é utilizado como uma das principais fontes de financiamento de curto prazo. Com bom guanxi, os empreendedores conseguem prolongar os prazos de pagamento com fornecedores locais e reduzir sua necessidade de capital de giro. Essa modalidade é popular, pois ela evita que algum tipo de constrangimento possa surgir entre os envolvidos, quando o assunto é dinheiro.

Enfim, independentemente do tamanho da loja, do tipo de negócio e da experiência no ramo, todos os empreendedores chineses de PMEs do Brasil, relacionados no presente estudo, consideram o guanxi essencial para financiar seus empreendimentos. Vale esclarecer que, devido à característica exploratória do estudo, bem como ao tamanho da amostra, as conclusões não podem ser generalizadas a toda a população de empreendedores chineses no Brasil; no entanto o estudo serve de base e auxilia a formulação de hipóteses e esclarecimento de idéias para outras pesquisas mais amplas e profundas.

\section{Artigo recebido em 21.05.2006. Aprovado em 03.03.2007.}

\section{RefERÊnCIAS BibliográficAs}

Banco Central da China. (2005). Relatório sobre a estrutura financeira de PMEs na China. Pequim: Citic Publishing House.

Carlisle, E., \&

Flynn, D. (2005).

Small business survival in China: guanxi, legitimacy, and social capital.
Journal of Developmental Entrepreneurship, 10(1), 79-96.

Departamento Estatístico da China. (2003).

China yearbook 2003. Pequim: Autor. 
Grossman, S. J., \&

Hart, O. (1986).

The costs and benefits of ownership: a theory of vertical and lateral integration. Journal of Political Economy, 94(4), 691-719.

Harris, M., \&

Raviv, A. (1989).

The design of securities. Journal of Financial Economics, 24(2), 255-287.

Harris, M., \&

Raviv, A. (1993).

The theory of security design: a survey [Working Paper $\left.N^{\circ} 135\right]$. University of Chicago, Chicago, IL, USA.

Hwang, K. (1987).

Face and favour: the chinese power game. American Journal of Sociology, 92(4), 944-974.

Jacobs, J. B. (1979).

A preliminary model of particularistic ties in chinese political alliance: Kanch'ing and Kuan-his in a rural taiwanese township. China Quarterly, 78, 237-273.

Jensen, M. C., \&

Meckling, W. H. (1976).

Theory of the firm: managerial behavior, agency costs and ownership structure. Journal of Financial Economics, 3(4), 305-360.

John, K., \&

Nachman, D. C. (1985).

Risky debt, investment incentive, and reputation in sequential equilibrium. The Journal of Finance, 40(3), 863878.
Kao, C. (1991).

Personal trust' in the large businesses in Taiwan: a traditional foundation for contemporary economic activities. In G. Hamilton (Ed.). Business networks and economic development in East and Southeast Asia. Hong Kong: Centre of Asian Studies, U. of Hong Kong.

King, A. A. (1996).

Kuan-his and network building. A sociological interpretation. In R. A. Brown. Chinese business enterprise: critical perspectives on business and management (Vol. 2, pp. 321-338). New York: TJ Press.

Kiong, T. C., \&

Kee, Y. P. (1998).

Guanxi bases, xinyong and chinese business network. The British Journal of Sociology, 49(1), 75-96.

Universidade de Finanças e Economia Central. (2001).

Relatório de pesquisa sobre PMEs na China. Shanghai, China: Autor.

Whyte, M. K. (1995).

The social roots of China's economic development. The China Quarterly, (Special Issue 144), 999-1019.

Yeung, M. (2006).

Is guanxi (relationship) a bridge to knowledge transfers. Journal of Business Research, 59(1), 130-139.

Zender, J. (1991).

Optimal financial instruments. Journal of Finance, 46(5), 1645-1663. 


\section{ANEXO 1}

Perguntas que fizeram parte do instrumento de pesquisa

\section{Parte I - Características do Empreendedor e do Empreendimento}

1 Qual a sua idade?

2 Que tipo de empreendimento você administra? Venda no Varejo ou Atacado?

3 Há quanto tempo administra este empreendimento?

4 Há quanto tempo está neste ramo?

5 Quantos funcionários trabalham no empreendimento?

6 Importa produtos da China?

7 Qual o faturamento da loja?

\section{Parte II - Guanxi dos Empreendedores}

8 Participa de quantas associações religiosas e não religiosas? Com que frequiência?

9 Você ou familiar direto ocupa algum posto de encarregado em algumas dessas associações? Qual?

10 Você freqüenta algum evento organizado por alguém? Se sim, com que frequiência?

11 Você organiza eventos? Se sim, com que frequiência?

12 Você tem parentes que trabalham no mesmo ramo?

13 Você tem amigos que trabalham no mesmo ramo?

Parte III - Formas de Financiamento

14 Como conseguiu capital para abrir seu negócio?

15 Que tipo de financiamento bancário você utiliza? Comente.

16 Que fontes de financiamentos de curto prazo você utiliza (e utilizava)? Por quê? Comente.

17 Há mais algum tipo de ajuda de parentes/amigos que são essenciais para seu negócio?

18 Considera essencial um bom guanxi para financiar seus negócios? 